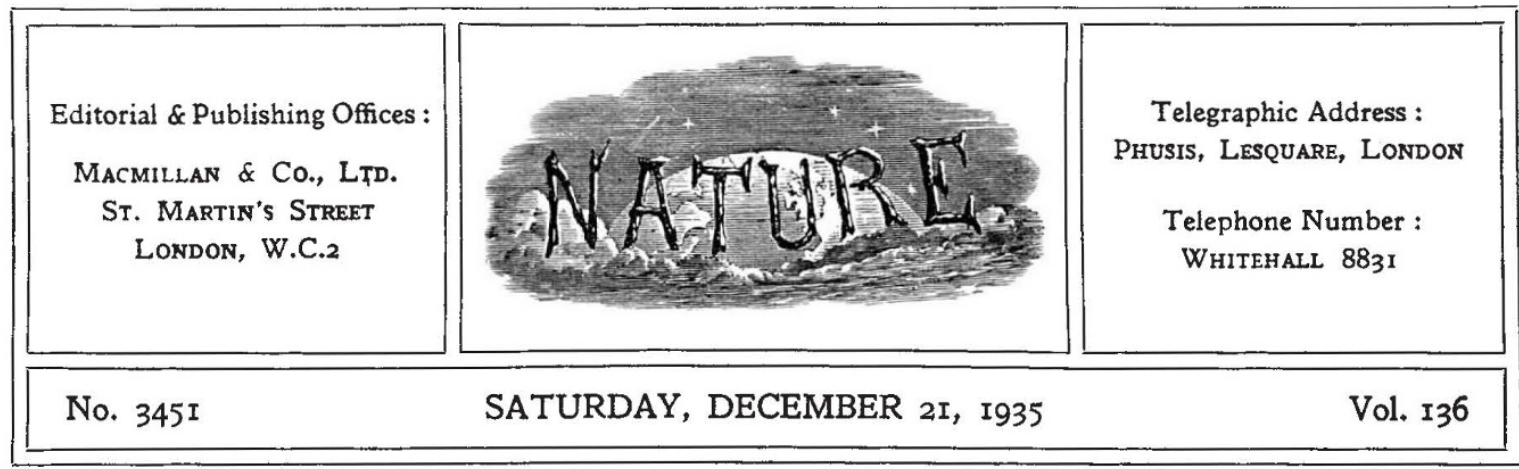

\title{
Scientific Humanism
}

$I^{x}$ $\mathrm{N}$ the preface of his admirable volume on the history of seventeenth century science, Prof. A. Wolf pleads for a new orientation in humanistic studies. The need for such a re-orientation, repeatedly urged in the columns of NATURE, is becoming more evident daily. On the Continent, reasonable persuasion and confidence in public education are increasingly regarded as exploded liberal superstitions. Blind obedience to leaders with supposedly exceptional gifts is more in keeping with the temper of the times, and if we record with gratitude the fact that Britain and the Scandinavian countries are least swayed by it up to date, it is all the more important to forestall a danger against which we have been amply forewarned. Men of science in Huxley's generation urged the claims of education with an assurance which is rarely voiced to-day. If we ask why this is so, one reason is not far to seek. The old tradition which exacted several years of classical study as the price of scientific education had at least one advantage. At the end of it, scientific worker and statesman had a common realm of discourse. In modern practice there is a complete dichotomy between an education which gives the statesman no prescience of the technical forces shaping the society in which he lives, and one which stimulates in the scientific worker little interest in the social impact of his own activities.

That there exists substantial reason for dissatisfaction with the exploits of contemporary statesmanship most scientific workers realise, and far-sighted leaders of scientific work like Sir Frederick Gowland Hopkins and Sir John Orr already recognise how the work of the man of science must inevitably suffer if society fails to make use of it. Sir Josiah Stamp's recent assault on the technocrats, in his Norman Lockyer Lecture before the British Science Guild on "The Calculus of Plenty", emphasises the absence of a common vocabulary to make the reasons for alarm rationally articulate. For the economist as such, plenty has little meaning aside from making what use we do make of our present resources with what social machinery we take for granted. The plenty of the scientific worker is a thermodynamic reality which resides in the balance sheet of human effort expended in securing available sources of power which could be applied to the satisfaction of our common mammalian requirements, if their use were rationally planned. The economist takes it as an axiom that people choose different things and does not concern himself with the fact that they have many common needs. The man of science sees society as an association of individuals with many basic requirements ; and, since people have no instinct to recognise minimal quantities of ascorbic acid in their diet, he cannot assume that people necessarily choose what is best for them without a science of human nature to enlighten their choice.

The disruptive movements which have overwhelmed Germany and Italy have been, first and foremost, youth movements. Some explain this as a symptom of large-scale unemployment. In part it may be. Still, it is important to remember that, under existing conditions, it is nobody's business to take stock of what resources for human welfare are made available by progressive scientific knowledge. Consequently youth has some excuse for feeling that intelligent leadership in social affairs is not likely to come from present political parties. The existing curriculum of humanistic studies does little to arrest the retreat from reason Social history is a pageant of political controversy in which matters of sentiment play a larger part 
than matters of fact, or a sequence of commercial enterprises solely controlled by the incentive of profit. What the expansion of maritime enterprise in the sixteenth century owed to rapid advances in nautical astronomy does not enter the picture. That witch-burning ceased almost as soon as the discovery that air has weight scattered the salamanders of alchemy, is shown to be more than a mere coincidence by the noteworthy experiment which Gassendi induced Colbert to witness. For purposes of history, as it is now taught, the general enlightenment of mankind proceeds with no acknowledgment of its debt to advancing knowledge of Nature.

At the end of the Great War, there was an articulate recognition of the danger of leaving the administration of a great country in the hands of civil servants trained in the tradition which prompted Mr. Gladstone's familiar query to Faraday. Pressure of informed opinion succeeded in securing a pivotal concession, when 'Everyday Science' was introduced as a compulsory subject in examinations for higher administrative posts of the Civil Service. The recent decision of the Commissioners to eliminate it will have deplorable consequences. Of late years there has been an encouraging sign of progress in the teaching of school science with more emphasis on its humanistic content. Many textbooks recently published show that more emphasis on the place of science in the education of the average citizen does not necessarily entail diffuse and vague courses of study conferring no knowledge which can be tested by customary examination standards. While the authors of such books deserve our gratitude, there is still ample scope for improvement, which will come, if teachers of science in the universities can be encouraged to co-operate with teachers of science in the school. In particular, there is need for more extensive as opposed to intensive teaching of isolated branches. With careful planning, and an enlightened social objective, this is not incompatible with examinable knowledge suitable for pupils of average intelligence.

The existence of the Civil Service examination in 'Everyday Science' acted as a catalyst. While it remained, it provided a unique opportunity for canalising the need for such co-operation by creating a demand for science courses in the universities suitable to students with a humanistic training. A beginning had been made under great difficulties with little appreciation from those who had been nurtured in the older tradition. If scientific men do not corporately influence the Commission to revise its decision, they will have forfeited an opportunity as well as a principle.

\section{The Examination of Examinations}

An Examination of Examinations:

being a Summary of Investigations on the Comparison of Marks allotted to Examination Scripts by Independent Examiners and Boards of Examiners, together with a Section on a Viva Voce Examination. By Sir Philip Hartog and Dr. E. C. Rhodes. (International Institute Examinations Enquiry.) Pp. 81. (London : Macmillan and Co., Ltd., 1935.) $1 s$.

$\mathrm{W}^{\mathrm{s}}$ HEN the late Prof. F. Y. Edgeworth made the startling discovery that twenty-eight experienced examiners could assign to the same piece of Latin prose marks varying from 45 to 100 per cent, he raised a doubt about the efficiency of public examinations which must have lingered ever since in the minds of persons concerned in their administration. No one questions that the major public examinations of Great Britain are conducted with scrupulous fairness, great pains being taken to secure by supervision and co. ordination of the examiners' work that the ultimate verdicts shall be as trustworthy as possible. The precautions worked out by Mr. David Mair when he was director of the Civil Service examinations are a noteworthy example of scientific efforts directed to this end; and the same thing may be said of the measures described by Dr. Crofts in his writings. Doubtless there are other authorities responsible for important examinations who approach the problems of administering them in the same scientific spirit; nevertheless, the results of inquiries which Prof. C. W. Valentine published in his book on the reliability of examinations showed only too clearly how doubtful an instrument for achieving its purpose an apparently welladministered examination may be.

The uneasiness stimulated by Prof. Valentine's book must be greatly increased by the pamphlet now written by Sir Philip Hartog and Dr. E. C. 